\title{
Technical solutions for the evaluation of the effect of explosion pressure when detoning various explosive loads in view of increasing the degree of societal security
}

\author{
Ilie-Ciprian Jitea ${ }^{1}$, Robert Laszlo ${ }^{1}$, Olga Miclea ${ }^{1}$, Anton Darsy ${ }^{2}$, and Claudius Popescu ${ }^{2}$ \\ ${ }^{1}$ National Institute for Research and Development in Mine Safety and Protection to Explosion - \\ INSEMEX Petrosani, Department of Safety of Explosion and Pyrotechnic Articles, G-ral V. Milea \\ Street 32-34, Petrosani, Romania \\ ${ }^{2}$ University of Petrosani, Doctoral School, Universitatii Street 22, Petrosani, Romania
}

\begin{abstract}
The scientific article highlights the synthesis of the research results to assess the effect of explosive pressure on the detonation of various quantities of explosives in order to ensure a predictable level of societal security. The results of the experimental researches highlighted in the scientific papers were obtained following the tests with explosive materials performed on different specially configured experimental assemblies in order to analyze the propagation of the pressure wave on a mobile platform with specially configured pressure and gas sensors as well as on the explosion pressure measuring sensors within two modern Kistler systems. The visualization of air pressure waves for the experiments performed with these working montages was done by using a high-speed camera based on the BOS effect applied on fast video filming with adequate quality characteristics on the number of frames per second and the resolution obtained.
\end{abstract}

\section{Introduction}

These hazards have a low probability of occurrence (the order of $10^{-7}$ to $10^{-6}$ per year) and are either not considered in structural design for economic reasons or addressed indirectly through passive protective measures rather than by structural calculations (NISTIR, 2007). Moreover, many codes and standards (eg. Eurocodes) offer limited information and explicit provisions for designing buildings or other infrastructure assets to resist such events. Therefore, engineers need more training and information so that they can provide designs that effectively enhance a building's response to such loading events.

Blasts (explosions) may occur due to deliberate (intentional) or accidental actions. Deliberate explosives come in two general categories, i.e., military and civilian (or commercial). Military explosives include explosives, such as bombs or plastic explosives

\footnotetext{
${ }^{*}$ Corresponding author: ciprian.jitea@insemex.ro
} 
used for demolitions. These are referred to as high explosives. Commercial explosives include such products as dynamite, TNT (trinitrotoluene) and Ammonium Nitrate (AN) among others. Note that Ammonium Nitrate has a long history in deliberate attacks. Accidental explosions may be also produced by explosives but more often are caused by natural gas.

Another classification makes difference between explosions in an enclosed space (internal explosion) and explosions in open space (external explosion). An internal (or confined explosion) will produce quasi-static pressure loads from the confinement of the products of the explosion. This pressure has a long duration in comparison to that of the shock pressure. External explosions (caused by high explosives) create a blast wave that is radiating away from the explosion source. If the blast wave intersects a reflecting surface (eg. a building façade), the pressure wave stagnates and then is reflected and reinforced with a factor between 2 to 10 , or even more.

Depending on the type and source of explosion, pressure can propagate as:

- Shock wave, which can be characterised by: are high-pressure blast waves that travel at a velocity faster than the speed of sound; shock waves are characterized by an instantaneous increase in pressure followed by a rapid decay.

- Pressure waves: are lower amplitude and travel below the speed of sound; are characterized by a more gradual increase in pressure than a ; shock wave, with a decay of pressure much slower than a shock wave.

In most cases, shock waves have a greater potential for damage and injury than pressure waves. Shock waves are associated with a detonation, while pressure waves are associated with a deflagration.

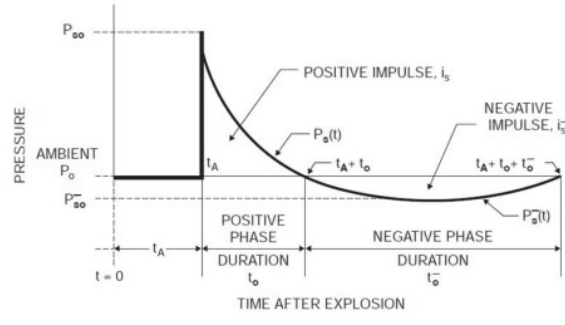

a)

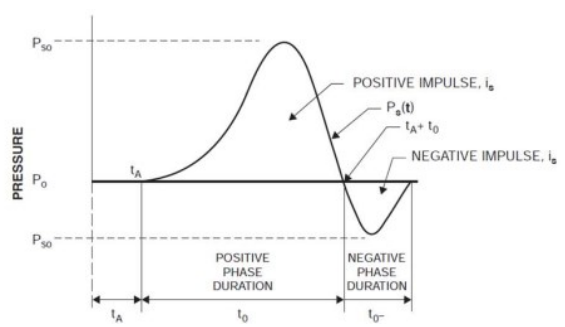

b)

Fig. 1. Blast pressure: a) pressure/duration curve for detonation in air; b) pressure/duration curve for deflagration.

The design of buildings and other infrastructure elements to the effects of blast require first the evaluation of loads and then the evaluation of structural response to loading.

The evaluation of the loads generated by a blast (internal, external) is a difficult task and depends on the correct prediction of blast parameters, i.e. blast pressures, load duration, impulse, shock wave velocity, and arrival times.

The structural response to blast loading is also very complex and depends on the dynamic response of blast-loaded structures: uncertainties of blast load calculations; timedependent deformations; effect of high strain rates; non-linear inelastic material behavior. In most cases of a deliberate (intentional) attack in the proximity of a building, the façade first and the structural system immediately following, are subjected to blast overpressure loading and emerging shrapnel or debris. The structure is therefore loaded by a combination of blast and impact loading. This interaction is very complicated and the effects have to be studied separately. 
Depending on the distance between the charge and the asset, blast loading may produce both local and global responses associated with different failure modes:

- A blast loading originating from standoff location can cause flexural failure of the entire structural element; the blast pressure wave acts as a uniformly distributed load. Failure modes associated with global response include flexure, direct shear.

- An explosion adjacent to the structural element usually causes a localized failure in shear-punching manner. This is caused by the high stiffness of structural elements which produces high inertial resistance to the blast (or impact) loading; a localized shear-punching failure takes place before the structural element as a whole is able to respond to the loading in a flexural way. In general, adjacent blast is less understood than distant blasts. Failure modes associated with local response (close-in effects): localized breaching, spalling, or punching shear

\section{Material and method}

\subsection{Computer simulation of an explosion produced by the detonation of an explosive charge made with a high power TNT type explosive, using $1.5 \mathrm{~kg}$ ETNT which is placed inside an ISO $1 \mathrm{C}$ container}

To solve the event scenario, a specialized software application of American origin type IMESAFR v2 Bundle was used (Fig.2) which allows a probabilistic assessment of the risk situations generated by the detonation of explosive charges of different types, based on the results grapho-analytical quantification of the associated specific hazards, in order to determine the level of safety or the corresponding degree of insecurity.
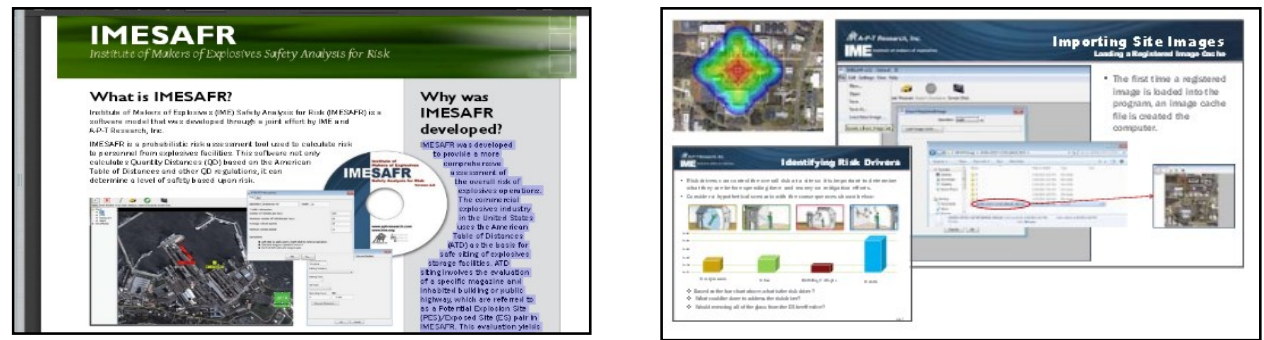

Fig. 2. Specialized computer application type IMESAFR V2 Bundle.

The use of the specialized IT application IMESAFR, in order to solve the event scenario, is based on the QRA (Quantitative Risk Assessment) model for estimating the annual probability of fatality, material damage, as well as major and minor traumas, and involves the 6 stages, logically ordered in the running architecture of the specialized program, respectively: 1. Defining the event scenario; Event and exposure analysis; It also includes user entries that describe the PES (Potential Explosion Site) scenario in relation to the ES (Exposure Site), the existing net explosive quantities (NEW); Calculation of the probability of explosion Taking into account human exposure; 2. Overpressure of the dynamic wave. Calculates the value of pressure and major and minor fatality / trauma mechanisms based on the impact impulse; 3. Structural response of the exposed site. Calculates the magnitude of the construction collapse mechanisms and broken windows, of accidents resulting in death / global damage to the building; 4. Debris (material resulting from the explosion and design of resulting fragments). Calculates the magnitude of hazardous residue mechanisms, accidents resulting in deaths and major and minor injuries; 5. Radiation and heat flux. Calculates the magnitude of the fatality mechanism caused by 
the thermal factor, only for event scenarios that are configured based on the use of hazardous materials with hazard class (Hazard Division) 1.3, according to Orange Book; 6.Determination and quantification of final results through analytical mechanisms of synergistic composition, aggregation and summation. Composing the total magnitude of all fatality mechanisms, calculates and solves risk situations, and assesses general uncertainty.

\section{2.-Experimental research on the effect of explosion pressure on the detonation of explosive charges for pressure and gas sensors}

\section{I) Open field experiments for air pressure wave on the gas TESTES sensor.}

In order to carry out research on the propagation of the pressure wave when detonating explosive charges, on the gas TESTES sensor, an experimental assembly was carried out as follows: a flat surface of open ground was selected, without obstacles; the gas TESTES sensor was placed at a distance of approx. $7 \mathrm{~m}$ from the explosion; 4 pressure sensors were cascaded (Two KISTLER explosion pressure measurement systems were used, so cylindrical sensors were placed on the bayonet sensors, both using IEPE sensors and LabAmp type 5165A4 amplifiers) at the following distances from the explosive charge: (sp1 pressure sensor at $3 \mathrm{~m}$; sp2 pressure sensor at $5 \mathrm{~m}$; sp3 pressure sensor at $7 \mathrm{~m}$; sp4 pressure sensor at $9 \mathrm{~m}$ ); metal support for suspending the explosive charge; the following types of RIOMAX and detonating cord explosive charges were used, with the following quantities: $143 \mathrm{~g}$ (RIOMAX cartridges) and $78 \mathrm{~g}$ (13 $\mathrm{ml}$ detonating cord with $6 \mathrm{~g} / \mathrm{ml}$ explosive).

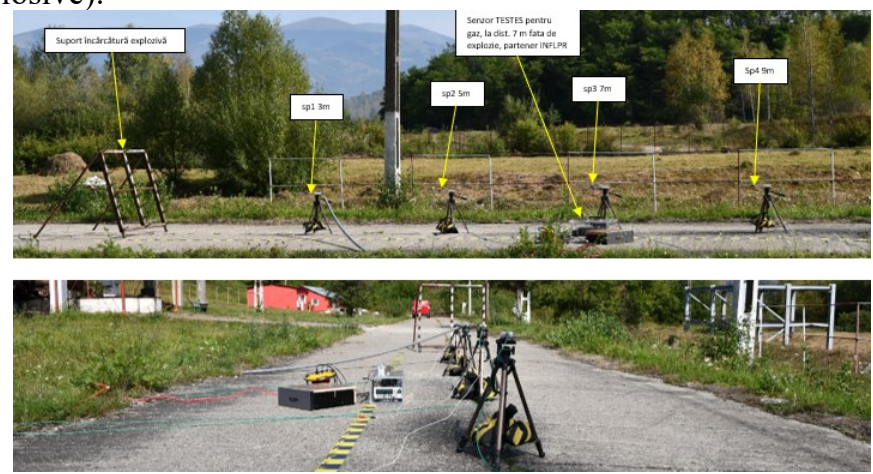

Fig. 3. In-line mounting of pressure sensors with gas TESTES sensor

\section{II) Open field experiments for air pressure wave on the TESTES pressure sensor.}

In order to carry out research on the propagation of the pressure wave when detonating explosive charges, on the gas TESTES sensor, an experimental assembly was carried out as follows: a flat surface of open ground was selected, without obstacles; the TESTES pressure sensor was placed at a distance of approx. $7 \mathrm{~m}$ from the explosion; 4 pressure sensors were cascaded (two KISTLER explosion pressure measurement systems were used, so cylindrical sensors were placed on the bayonet sensors, both using IEPE sensors and LabAmp type 5165A4 amplifiers) at the following distances from the explosive charge: (sp1 pressure sensor at $3 \mathrm{~m}$; sp2 pressure sensor at $5 \mathrm{~m}$; sp3 pressure sensor at $7 \mathrm{~m}$; sp4 pressure sensor at $9 \mathrm{~m}$ ); metal support for suspending the explosive charge; the following types of RIOMAX and detonating cord explosive charges were used, with the following quantities: 143g (RIOMAX cartridges), respectively $60 \mathrm{~g}(10 \mathrm{ml}$ detonating cord $6 \mathrm{~g} / \mathrm{ml}$ explosive). 

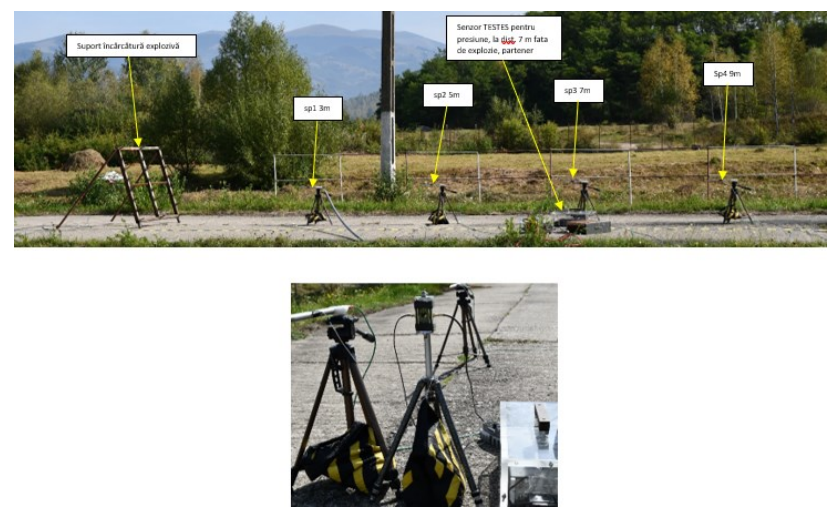

Fig. 4. In-line mounting of pressure sensors with pressure TESTES sensor

\section{Results and discussion}

3.1. The results of the computer simulation of an explosion produced by the detonation of an explosive charge carried out with a high power explosive type TNT, using $1.5 \mathrm{~kg}$ ETNT which is placed inside an ISO $1 \mathrm{C}$ type container (figures 5,6,7):

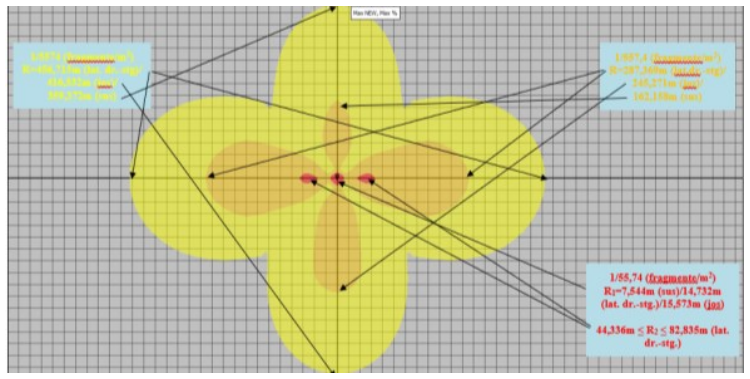

Fig. 5. Contour map on the design of fragments resulting from the detonation of an explosive charge of $1.5 \mathrm{~kg}$ ETNT

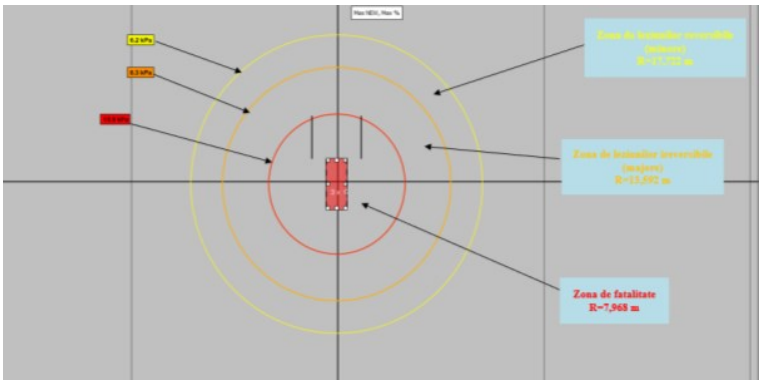

Fig. 6. Overpressure curves generated by the detonation of an explosive charge of $1.5 \mathrm{~kg}$ ETNT 


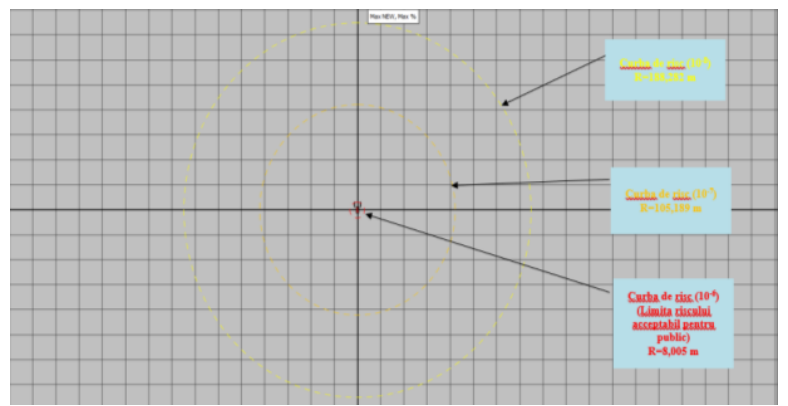

Fig. 7. Risk curves generated by the detonation of a load of $1.5 \mathrm{~kg}$ ETNT explosives

\subsection{Open field experiments for air pressure wave on the gas TESTES sensor}

a) The results of the cylindrical pressure curve sensors for each distance and for each type of explosive are as follows:

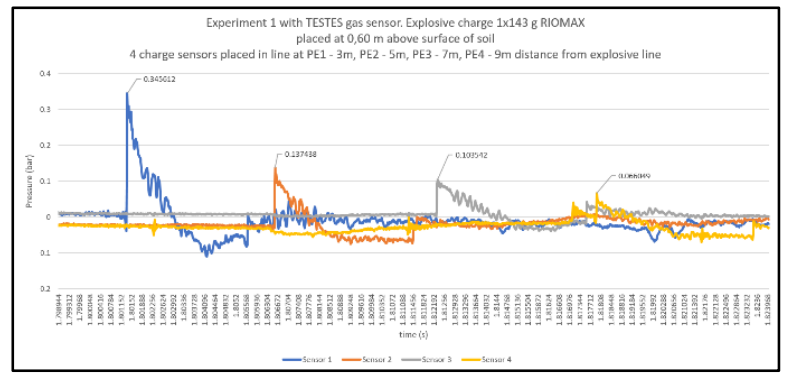

Fig. 8. Detail of the pressure increase ramp for a $143 \mathrm{~g}$ explosive charge

Maximum values for PE1, PE2, PE3 and PE4 for $143 \mathrm{~g}$ explosive charge

\begin{tabular}{|l|l|l|l|}
\hline $\begin{array}{l}\text { PE1 } \\
\text { (mbar) }\end{array}$ & $\begin{array}{l}\text { PE2 } \\
\text { (mbar) }\end{array}$ & $\begin{array}{l}\text { PE3 } \\
\text { (mbar) }\end{array}$ & $\begin{array}{l}\text { PE4 } \\
\text { (mbar) }\end{array}$ \\
\hline 345.61 & 137.43 & 103.54 & 66.049 \\
\hline
\end{tabular}

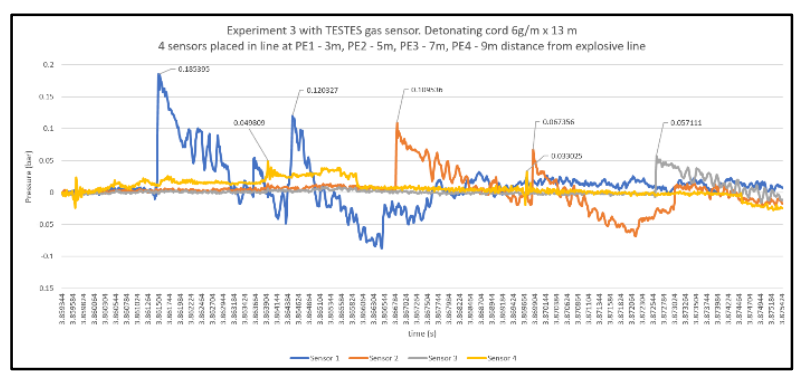

Fig. 9. Detail of the pressure increase ramp for detonating cord $78 \mathrm{~g}$ explosive

Maximum values for PE1, PE2, PE3 and PE4 for detonating cord $78 \mathrm{~g}$ explosive

\begin{tabular}{|l|l|l|l|}
\hline $\begin{array}{l}\text { PE1 } \\
\text { (mbar) }\end{array}$ & $\begin{array}{l}\text { PE2 } \\
\text { (mbar) }\end{array}$ & $\begin{array}{l}\text { PE3 } \\
\text { (mbar) }\end{array}$ & $\begin{array}{l}\text { PE4 } \\
\text { (mbar) }\end{array}$ \\
\hline 185.39 & 109.53 & 57.111 & 49.809 \\
\hline
\end{tabular}

b) The results of the bayonet sensors on the pressure curves for each distance and for each 
type of explosive are the following:

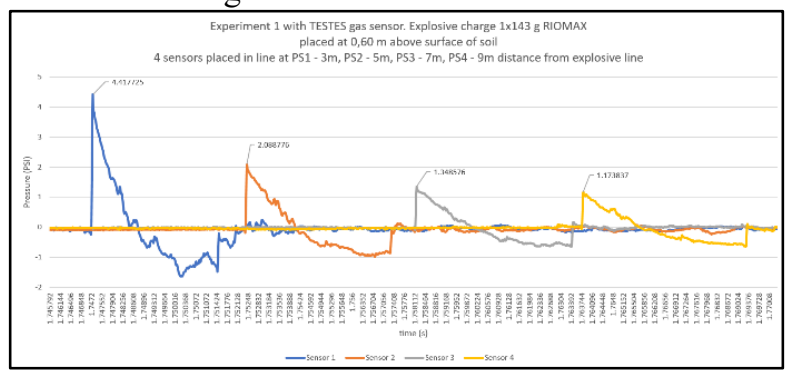

Fig. 10. Detail of the pressure increase ramp for $143 \mathrm{~g}$ explosive

Maximum values for sp1, sp2, sp3 and sp4 for $143 \mathrm{~g}$ explosive

\begin{tabular}{|l|l|l|l|}
\hline $\begin{array}{l}\text { Sp1 } \\
\text { (mbar) }\end{array}$ & $\begin{array}{l}\text { Sp2 } \\
\text { (mbar) }\end{array}$ & $\begin{array}{l}\text { Sp3 } \\
\text { (mbar) }\end{array}$ & $\begin{array}{l}\text { Sp4 } \\
\text { (mbar) }\end{array}$ \\
\hline 304.59 & 144.01 & 92.981 & 80.933 \\
\hline
\end{tabular}

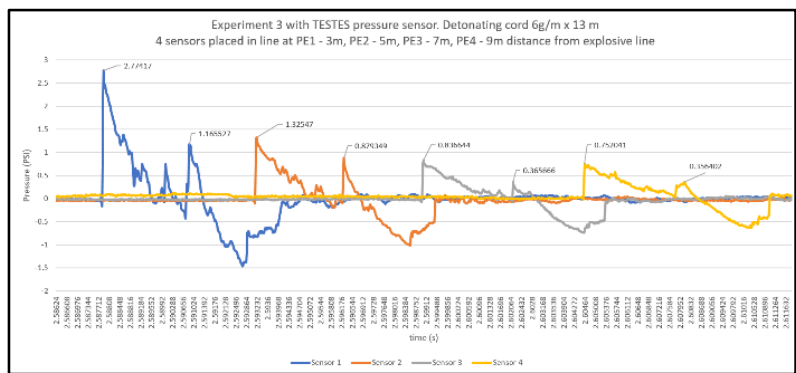

Fig. 11. Detail of the pressure increase ramp for detonating cord $78 \mathrm{~g}$ explosive

Maximum values for $\mathrm{sp} 1, \mathrm{sp} 2, \mathrm{sp} 3$ and $\mathrm{sp} 4$ for $78 \mathrm{~g}$ explosive

\begin{tabular}{|l|l|l|l|}
\hline $\begin{array}{l}\text { Sp1 } \\
\text { (mbar) }\end{array}$ & $\begin{array}{l}\text { Sp2 } \\
\text { (mbar) }\end{array}$ & $\begin{array}{l}\text { Sp3 } \\
\text { (mbar) }\end{array}$ & $\begin{array}{l}\text { Sp4 } \\
\text { (mbar) }\end{array}$ \\
\hline 191.27 & 91.387 & 57.684 & 51.851 \\
\hline
\end{tabular}

\subsection{Open field experiments for air pressure wave on the pressure TESTES sensor}

a) The results of the cylindrical sensors on the pressure curves for each distance and for each type of explosive are the following:

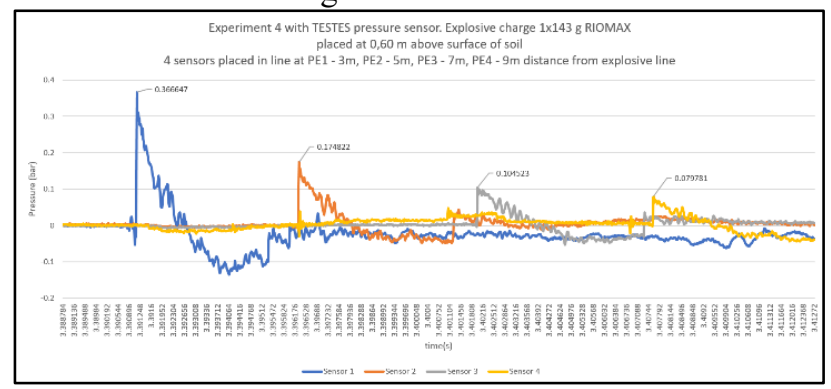

Fig. 12. Detail of the pressure increase ramp for $143 \mathrm{~g}$ explosive

Maximum values for PE1, PE2, PE3 and PE4 for $143 \mathrm{~g}$ explosive 


\begin{tabular}{|l|l|l|l|}
\hline $\begin{array}{l}\text { PE1 } \\
\text { (mbar) }\end{array}$ & $\begin{array}{l}\text { PE2 } \\
\text { (mbar) }\end{array}$ & $\begin{array}{l}\text { PE3 } \\
\text { (mbar) }\end{array}$ & $\begin{array}{l}\text { PE4 } \\
\text { (mbar) }\end{array}$ \\
\hline 366.64 & 174.82 & 104.52 & 79.781 \\
\hline
\end{tabular}

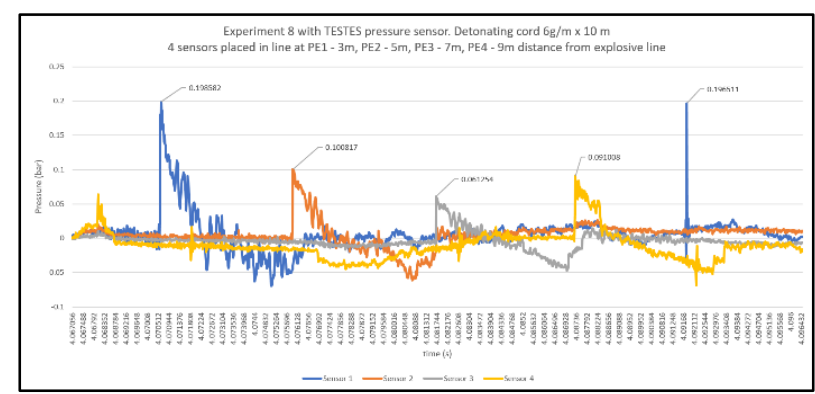

Fig. 13. Detail of the pressure increase ramp for detonating cord $60 \mathrm{~g}$ explosive

Maximum values for PE1, PE2, PE3 and PE4 for detonating cord $60 \mathrm{~g}$ explosive

\begin{tabular}{|l|l|l|l|}
\hline $\begin{array}{l}\text { PE1 } \\
\text { (mbar) }\end{array}$ & $\begin{array}{l}\text { PE2 } \\
\text { (mbar) }\end{array}$ & $\begin{array}{l}\text { PE3 } \\
\text { (mbar) }\end{array}$ & $\begin{array}{l}\text { PE4 } \\
\text { (mbar) }\end{array}$ \\
\hline 198.58 & 100.81 & 61.254 & 91.008 \\
\hline
\end{tabular}

b) The results of the bayonet sensors on the pressure curves for each distance and for each type of explosive are the following:

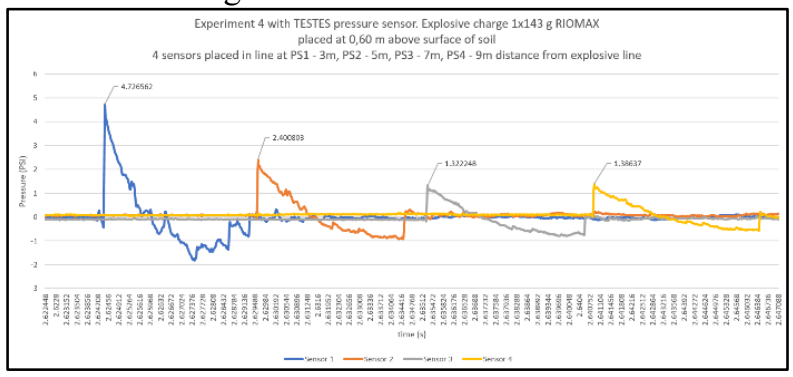

Fig. 14. Detail of the pressure increase ramp for $143 \mathrm{~g}$ explosive

Maximum values for $\mathrm{Sp} 1, \mathrm{Sp} 2, \mathrm{Sp} 3$ and $\mathrm{Sp} 4$ for $143 \mathrm{~g}$ explosive

\begin{tabular}{|l|l|l|l|}
\hline $\begin{array}{l}\text { Sp1 } \\
\text { (mbar) }\end{array}$ & $\begin{array}{l}\text { Sp2 } \\
\text { (mbar) }\end{array}$ & $\begin{array}{l}\text { Sp3 } \\
\text { (mbar) }\end{array}$ & $\begin{array}{l}\text { Sp4 } \\
\text { (mbar) }\end{array}$ \\
\hline 325.88 & 165.52 & 91.165 & 95.586 \\
\hline
\end{tabular}

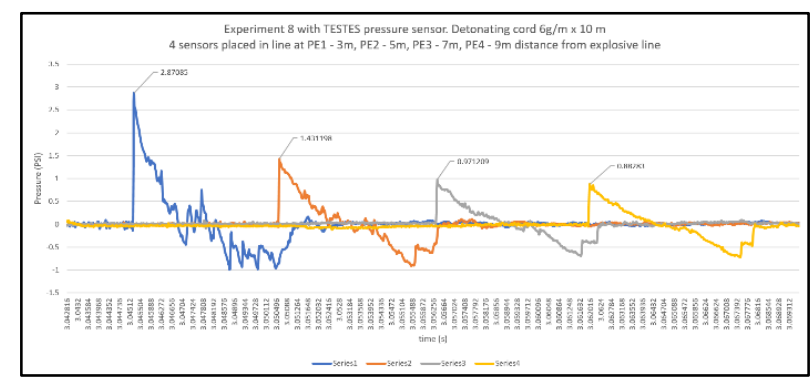

Fig. 15. Detailing of the pressure rise ramp for detonating cord of $60 \mathrm{~g}$ explosive 
Maximum values for $\mathrm{Sp} 1, \mathrm{Sp} 2, \mathrm{Sp} 3$ and $\mathrm{Sp} 4$ for detonating wick $60 \mathrm{~g}$ explosive

\begin{tabular}{|l|l|l|l|}
\hline $\begin{array}{l}\text { Sp1 } \\
\text { (mbar) }\end{array}$ & $\begin{array}{l}\text { Sp2 } \\
\text { (mbar) }\end{array}$ & $\begin{array}{l}\text { Sp3 } \\
\text { (mbar) }\end{array}$ & $\begin{array}{l}\text { Sp4 } \\
\text { (mbar) }\end{array}$ \\
\hline 197.93 & 98.677 & 66.962 & 60.868 \\
\hline
\end{tabular}

\subsection{Example of using high speed camcorder PHANTOM VEO 710}

The visualization of the air pressure wave for the experiment with $143 \mathrm{~g}$ explosive and $78 \mathrm{~g}$ explosive of detonating cord (the undistorted circular contour is observed next to the pressure sensors) using the BOS (Background Oriented Schlieren) effect, applied on fast video filming with $8000 \mathrm{fps}$ and 1280 resolution $\mathrm{x} 720$ pixels.
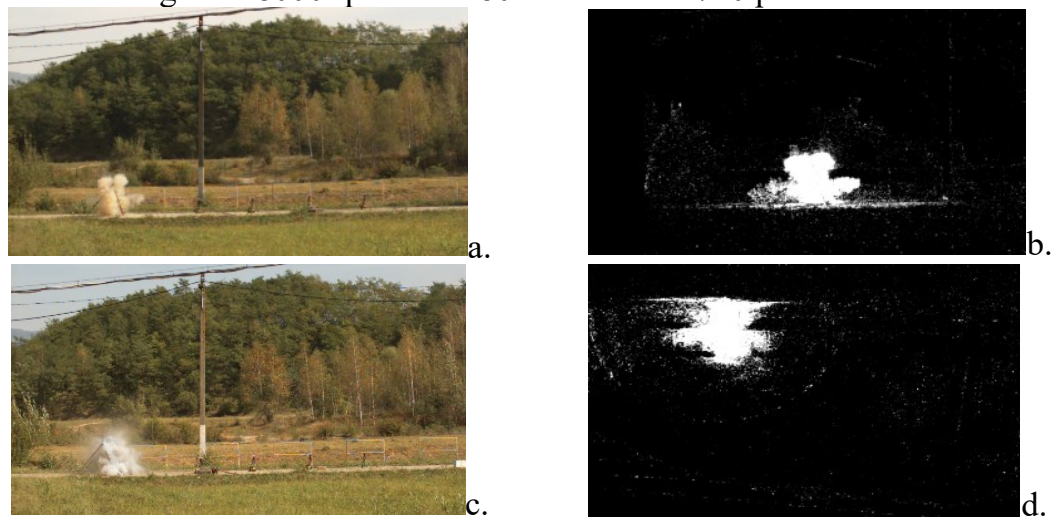

Fig.16. Air pressure wave view for experiment $143 \mathrm{~g}$ explosive $(\mathrm{a}, \mathrm{b})$ and $78 \mathrm{~g}$ detonating cord explosive (c, d)

The effects of explosions on buildings and people are summarized in the tables. 1 and 2

Table 1. Estimated damage attributed to an overpressure resulting from an explosion

\begin{tabular}{|l|l|}
\hline $\begin{array}{c}\text { Overpressure } \\
\text { (mbar) }\end{array}$ & Estimated damage \\
\hline 2,07 & Occasional burglary of large windows that are already subject to stress. \\
\hline 2,075 & Glass breakage caused by loud noises (143 dB) or sonic booms. \\
\hline 6,89 & Breaking small windows subject to stress. \\
\hline 10,34 & Cracking of normal glass. \\
\hline 27,58 & Some damage to the ceiling of the houses; 10\% breaking windows. \\
\hline 27,58 & Minor, limited damage to the structure. \\
\hline $34,47-68,94$ & Normally destroyed windows; damage occurs to the window frames. \\
\hline 48,26 & Minor damage to house structure. \\
\hline 68,94 & The houses are made uninhabitable due to partial demolition. \\
\hline $68,94-137,89$ & $\begin{array}{l}\text { Dislocation and buckling of grooved metal panels, wooden panels of houses are } \\
\text { discarded. }\end{array}$ \\
\hline $68,94-551,58$ & $\begin{array}{l}\text { Mild to severe lesions (eg skin lesions due to shards of airborne glass and other } \\
\text { projectiles). }\end{array}$ \\
\hline 89,63 & Slight distortion of steel frames in reinforced buildings. \\
\hline 137,89 & Partial destruction of the walls and roofs of houses. \\
\hline $137,89-206,84$ & Dislocation of unreinforced walls or slag brick walls. \\
\hline 158,57 & Lower limit of serious damage to the structure. \\
\hline 172,36 & $50 \%$ destruction of brick houses. \\
\hline 206,84 & Distortion of buildings with steel frames; can be removed from the foundation. \\
\hline $206,84-275,79$ & Demolition of buildings from panels without steel frames (unarmed). \\
\hline 275,79 & Breaking the fittings of light industrial buildings. \\
\hline
\end{tabular}




\begin{tabular}{|c|c|}
\hline 344,74 & Overturning wooden support poles. \\
\hline $344,74-482,63$ & Almost complete destruction of houses. \\
\hline 482,63 & Overturning of loaded road trains. \\
\hline $482,63-551,58$ & Transverse shearing damages 8 to 12 inch thick unreinforced bricks. \\
\hline 620,52 & Demolition of loaded road trains. \\
\hline 689,47 & $\begin{array}{l}\text { Probable complete destruction of the building. } 99 \% \text { deaths in the population } \\
\text { exposed as a result of the direct effects of the explosion. }\end{array}$ \\
\hline
\end{tabular}

Table 2. Injury to the human body due to explosion overpressure

\begin{tabular}{|c|l|}
\hline $\begin{array}{c}\text { Overpressure } \\
\text { (mbar) }\end{array}$ & \multicolumn{1}{c|}{ Effects } \\
\hline 350 & The limit of rupture of the eardrum \\
\hline 700 & Limit for lung damage \\
\hline 1000 & Up to 50\% rupture of the eardrum in the exposed population \\
\hline 1800 & $1 \%$ mortality \\
\hline 2100 & $10 \%$ mortality \\
\hline 2600 & $50 \%$ mortality \\
\hline 3000 & $90 \%$ mortality \\
\hline 3500 & $99 \%$ mortality \\
\hline
\end{tabular}

\section{Conclusions}

The results highlighted in the paper were obtained both by computer simulation of an explosion generated by the detonation of an explosive charge made with a high power explosive type TNT (1.5 kg ETNT), and by evaluating the effect of explosion pressure on detonation explosive materials, using specialized gas and pressure sensors. The results of the experimental researches highlighted in the scientific papers were obtained following the tests with explosive materials performed on different specially configured experimental assemblies in order to analyze the propagation of the pressure wave on a mobile platform with specially configured pressure and gas sensors as well as on the explosion pressure measuring sensors within two modern Kistler systems. The visualization of air pressure waves for the experiments performed with these working montages was done by using a high-speed camera based on the BOS effect applied on fast video filming with adequate quality characteristics on the number of frames per second and the resolution obtained.

\section{References}

1. F. Dinu, D. Dubina, I. Marginean, Improving the structural robustness of multi-story steel-frame buildings, Structure and Infrastructure Engineering, 11, Issue 8, Pg. 1028-1041

2. BA. Izzuddin, Imperial College, Ductility assessment for an idealized elasto-plastic structural system subject to an instantaneous applied load. (Internal discussion document, London, UK, 2004)

3. BIPS 05, Preventing Structures from Collapsing to Limit Damage to Adjacent Structures and Additional Loss of Life when Explosives Devices Impact Highly Populated Urban Centers, (Homeland Security, 2011)

4. N. F. Somes, Abnormal Loading on Buildings and Progressive Collapse, (Building Practices for Disaster Mitigation (Wright, Kramer and Culver, eds.), Building Science Series No. 46, National Bureau of Standards, Washington, DC, 1973)

5. E.F.P. Burnett, The Avoidance of Progressive Collapse: Regulatory Approaches to the Problem, (Report No. NBS-GCR-75-48, National Bureau of Standards, Washington, DC, 1975b)

6. NBS, Protection of buildings against explosions, (Publication 244, Steel Construction Institute 1999) 